\section{RELATED EVENTS CALENDAR}

The 20th Annual Meeting of the Federation of Analytical Chemistry and Spectroscopy Societies (FACSS). This will be held in Detroit, Michigan, during the week of October 17-22, 1993. The deadline for submission of titles and a preliminary 100 word brief is February 1, 1993. For further information please contact: FACSS, P.O. Box 278, Manhattan, KS 66502, or phone (301)-846-4797.
Ninth International Conference on Secondary Mass Spectrometry. SIMS IX will be held November 712, 1993, at the Hotel Yokohama and SangyoBoeki Center Building, Yokohama, Japan. The deadline for the submission of abstracts is May 15, 1993. The deadline for advanced registration is September 1 , 1993. The official language of the conference is English.

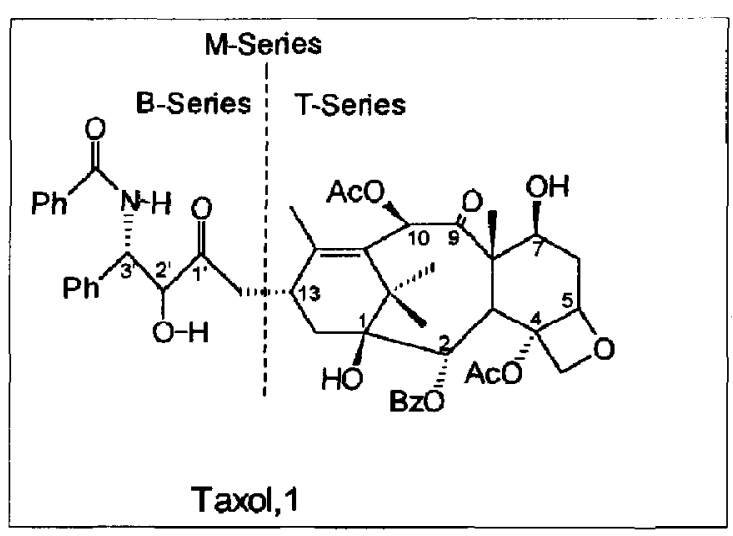

\section{Erratum}

\section{Dear Editor}

The structure published in our article "The Mass Spectrometry of Taxol," appearing in JASMS 1992, 3, 672-679 was incorrect. The acetyl group at the 4-posi- tion was left off, and the oxetane oxygen was shown at the 4 position and should have been at the 5 position, as shown above.

Thomas D. McClure, Mark L. J. Reimer, and Karl H. Schram 